\title{
Laminar Flame Characteristics of Premixed Methanol-Water-Air Mixture
}

\author{
Zhennan Zhu ${ }^{1}$, Kun Liang ${ }^{2, *}$, Xinwen Chen ${ }^{3, *}$, Zhongwei Meng ${ }^{1}$, Wenbin $\mathrm{He}^{1}$ and Hao Song ${ }^{1}$ \\ 1 Key Laboratory of Fluid and Power Machinery, Ministry of Education, Xihua University, \\ Chengdu 610039, China; zz293@sussex.ac.uk (Z.Z.); mengzw@mail.xhu.edu.cn (Z.M.); \\ wbhe@xhu.edu.cn (W.H.); 0720120016@mail.xhu.edu.cn (H.S.) \\ 2 Department of Engineering and Design, University of Sussex, Falmer, Brighton BN1 9QT, UK \\ 3 Department of Mechanical Engineering, Yangzhou University, Yangzhou 225012, China \\ * Correspondence: kun.liang@sussex.ac.uk (K.L.); 007208@yzu.edu.cn (X.C.)
}

Received: 22 November 2020; Accepted: 8 December 2020; Published: 9 December 2020

check for updates

\begin{abstract}
Methanol is hygroscopic in a gaseous state and is a promising alternative fuel for internal combustion engines. It is understood that adding water can improve the antiknock performance for spark ignition engines, but this will also affect the flame speed and stability. In this work, laminar flame characteristics of methanol/water/air mixtures were experimentally investigated at a temperature range of 380-450 K, a pressure range of 1-4 bar, and water fractions (vaporous water molar fraction in the water-methanol fuel gas) of $0-40 \%$. The results show that laminar burning velocity increases with temperature but decreases with pressure. The burning velocity decreases linearly with water fraction at a stoichiometric ratio. For rich mixtures and high pressures, the laminar flames tend to be more sensitive to stretch and, thus, more prone to being unstable. Increasing the water fraction can slightly increase the Markstein length. Increasing the initial pressure enhances the general flame instability, while increasing the initial temperature suppresses the general flame instability. Increasing the water fraction can lead to a decreasing thermal expansion ratio and an elevated flame thickness, both of which can lead to a suppression of hydrodynamic instability. An increase in the water fraction decreases the Lewis number, resulting in preferential diffusion instability. There is no direct relationship between the onset of cellularity and general flame instability.
\end{abstract}

Keywords: methanol; water; combustion; laminar burning velocity; Markstein length; flame instability

\section{Introduction}

Increasingly serious environmental pollution and energy shortage have drawn widespread concerns and are strongly require promising replacements for conventional fossil fuels [1]. Different kinds of alternative fuels are becoming growing interests including natural gas, hydrogen, and alcohols [2-4]. Both methanol and ethanol are being used more and more widely. The addition of ethanol to spark ignition engines can decrease some pollutants but can also increase others $[5,6]$. Methanol is regarded as an ideal alternative fuel for internal combustion engines (IC engines) owing to its high octane rating, high latent heat, low combustion temperatures, and relatively clean emissions [7-9], which can help to achieve higher power output, higher efficiency, and lower pollution. Methanol can be produced through fossil fuel-based feedstocks, as well as gasification of wood, agricultural byproducts, and urban waste [10]. Methanol is hygroscopic, as purified gaseous methanol can absorb water from the atmosphere, which can improve the antiknock performance but also lead to a decrease in the calorific value and phase separation of methanol-gasoline blends [7]. Water may cause negative effects on the combustion performance of methanol fuels. 
Laminar flame characteristics are essential parameters of fuels and are closely related to the performance when used in internal combustion engines. Laminar flame velocity is highly related to the burning duration, power output, and efficiency. It also can be used for validation of the chemical kinetic mechanism and prediction of the turbulent combustion stage. The flame instability strongly influences the cyclical variation $[11,12]$. Laminar flame characteristics can be investigated via many methods including constant volume chambers (CVCs).

To date, a number of studies on methanol burning and mechanisms have been conducted. Vancoillie et al. [13] investigated the effect of nitrogen and water vapor dilution on the laminar burning velocity of methanol flame through heat flux method experiments and simulation. It was found that the chemical effect was negligible when diluted by nitrogen and when the water fraction (vaporous water molar fraction in the water-methanol fuel gas) was lower than $20 \%$. The effect of dilution on laminar burning velocity was regarded as adequately approximated by a linear decrease in terms of the diluent molar fraction. $\mathrm{Li}$ et al. [14] developed a mechanism for the prediction of $\mathrm{CO}, \mathrm{CH}_{2} \mathrm{O}$, and methanol combustion. Katoch et al. [15] used a mesoscale diverging channel method to measure the laminar burning velocity and compared the results with those from a kinetic simulation. It was found that the values from experiments and simulations agreed well at low temperatures, but the San Diego [16] and Li mechanisms [14] would overpredict the burning velocity.

Despite the number of studies on methanol mentioned above, most of them focused on the burning velocity measurements without taking water vapor into account. There is no study in the literature on the flame stability characteristics of methanol/water mixture. Note that flame instability is also essential for understanding properties of fuels, and burning at high temperature and pressure with absorbing water is closer to a real combustion atmosphere for methanol. It is significant to comprehensively investigate both the burning velocity and the flame instability of methanol/water vapor mixtures. In this work, a constant volume chamber with a Schlieren imaging system was applied to investigate the laminar flame propagation speed and flame instabilities of methanol/water vapor mixtures at high temperatures ranging up to $450 \mathrm{~K}$ and high pressures ranging up to 4 bar.

\section{Experimental Set-Up}

The experiments were conducted using a constant volume chamber (CVC) and a Schlieren imaging system shown as Figure 1. The CVC had a pair of windows with diameter of $40 \mathrm{~mm}$ for imaging. A light-emitting diode (LED; green Prolight Power Star/O, power $1 \mathrm{~W}$ ) was used for illumination. A high-speed camera (Photron $1024 \mathrm{PCI}$ ) with a $512 \times 512$ pixel resolution and a frame rate of 3000 frames per second (fps) was used for photographing. The Schlieren system for this work was a folded z-type arrangement, and two oppositely tilted off-axis spherical mirrors were applied to produce the collimated beam. The constant volume chamber was a stainless-steel spherical one with a diameter of $160 \mathrm{~mm}$, allowing a maximum working pressure of 34 bar inside. The initial temperature control was achieved by a fan oven enclosing the CVC, which could heat the chamber up to $450 \mathrm{~K}$. Two electrodes formed an ignition gap at the center of the chamber. The mass flow rate of the intake air was monitored and controlled by a mass flow controller. A subsequent injection block was adopted to heat the air and evaporate the liquid fuel. A syringe controller was used to control the volume and injection speed of the liquid fuel. Table 1 shows the test conditions of burning velocity for methanol/water mixtures. For all test conditions, there was a duration of $5 \mathrm{~min}$ before ignition to make the mixtures homogeneous in the chamber, as suggested in $[7,17]$.

Table 1. Test conditions of combustion for methanol/water mixtures.

\begin{tabular}{cc}
\hline Parameter (Unit) & Value \\
\hline Initial temperature $T_{u}(\mathrm{~K})$ & 380,450 \\
Initial pressure $p_{u}(\mathrm{bar})$ & $1,2,4$ \\
Equivalence ratio $\Phi$ & $0.7-1.4($ interval of 0.1$)$ \\
Fraction of $\mathrm{H}_{2} \mathrm{O}(\%)$ & $0(\mathrm{~W} 0), 20(\mathrm{~W} 20), 40(\mathrm{~W} 40)$ \\
\hline
\end{tabular}




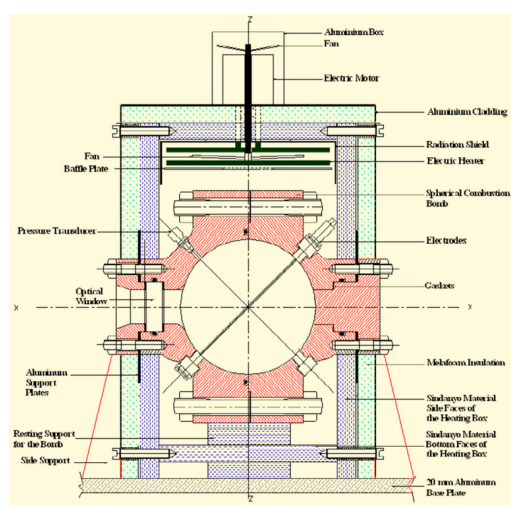

(a)

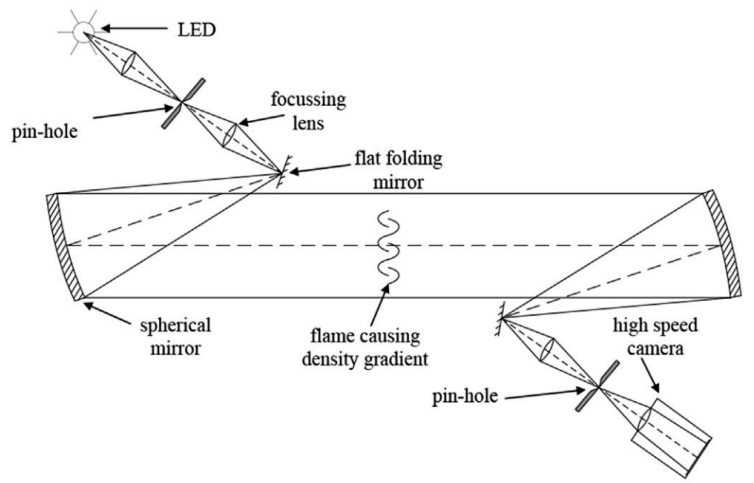

(b)

Figure 1. Schematic of the (a) constant volume combustion bomb with optical window for Schlieren imaging system, and (b) arrangement of folded z-type Schlieren imaging system [10].

\section{Data Processing}

\subsection{Extraction of Flame Radius}

The extraction process of the flame radius is shown in Figure 2. As shown, five main steps were implemented via a MATLAB code. The midpoint of the red horizontal line (point $Q$ in Figure 2) was chosen as the center of the flame. Based on the center point, six radii, with an angle interval of $60^{\circ}$, were defined after identifying the flame front, and their average was computed to increase accuracy. Furthermore, values of flame radius at the ignition electrode were invalid due to the impact of the boundary layer, and these values were excluded. To ensure that the influence of ignition energy and pressure variations was negligible, images with $6 \mathrm{~mm}<R<25 \mathrm{~mm}$ were deemed suitable for computing the flame propagation speed [18]. Since the diameter of the window was $40 \mathrm{~mm}$, images with $6 \mathrm{~mm}<R<20 \mathrm{~mm}$ were selected. For each test condition, 30-50 flame images of the propagation process with fixed time interval were selected to calculate the flame propagation speed (through the differences in radius and the time interval).

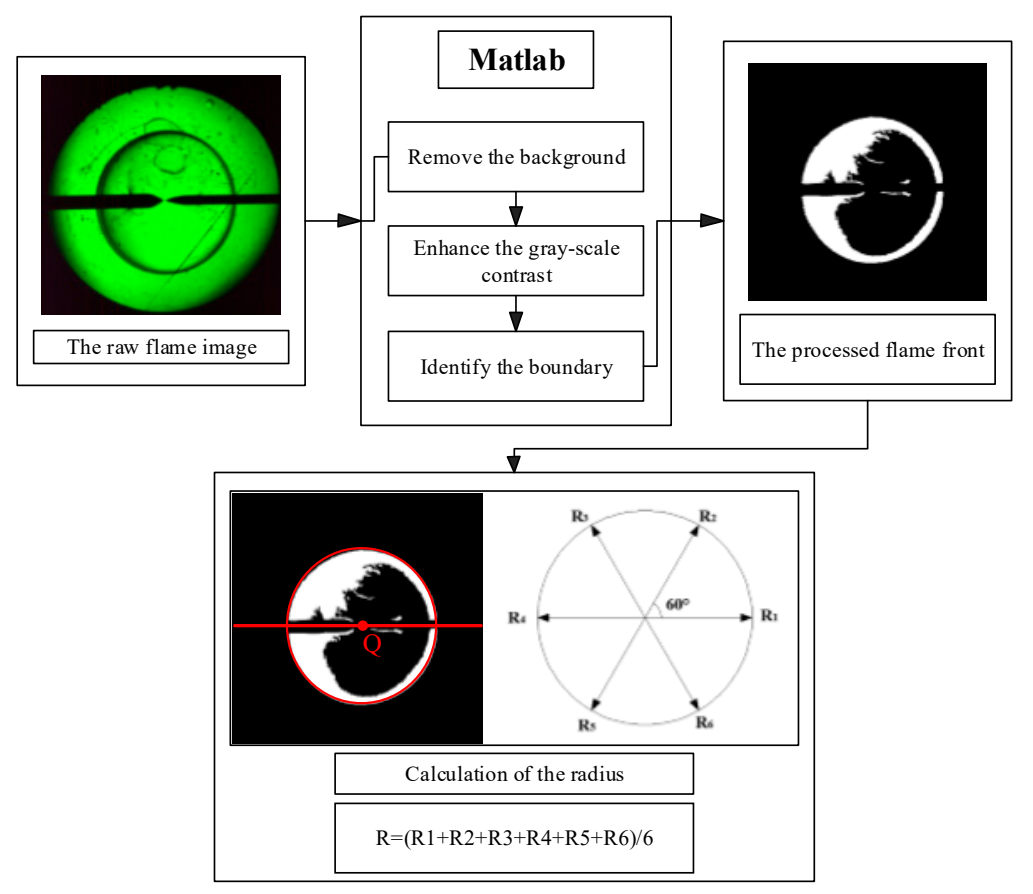

Figure 2. Flowchart of flame radius extraction from methanol/water combustion data. 


\subsection{Data Reduction}

The stretched propagation flame speed $S_{\mathrm{n}}$ can be defined as the derivative of the flame radius $R_{\mathrm{u}}$ with respect to time $t$, as shown in Equation (1).

$$
S_{\mathrm{n}}=d R_{\mathrm{u}} / d t
$$

The flame stretch rate $K$ is obtained through Equation (2).

$$
K=d(\ln A) / d t=2 S_{\mathrm{n}} / R_{u}=\kappa S_{\mathrm{n}},
$$

where $\kappa=2 / R_{\mathrm{u}}$ is the curvature of the flame front.

According to Chen [19], in order to get the unstretched flame propagation speed $S_{1}$ and Markstein length $L_{\mathrm{b}}$ (indicating the sensitivity of the flame to stretch), there are three models that can be used, which are the linear model (Equation (3)), nonlinear model I (Equation (4)) [20], and nonlinear model II (Equation (5)) [21].

$$
\begin{gathered}
S_{1}-S_{\mathrm{n}}=L_{\mathrm{b}} K \\
S_{\mathrm{n}}=S_{1}-S_{1} L_{\mathrm{b}} \kappa \\
\ln \left(S_{\mathrm{n}}\right)=\ln \left(S_{1}\right)-S_{1} L_{\mathrm{b}} \kappa / S_{\mathrm{n}}
\end{gathered}
$$

The inaccuracy of the linear model has been proven when the equivalence ratio is not stoichiometric. The nonlinear model I has been proven to be the most accurate for mixtures with Lewis number $L e>1$, while nonlinear model II has been proven to be the most accurate for mixtures with Lewis number $L e<1$. The Lewis number can be obtained as follows:

$$
L e=\lambda / \rho_{\mathrm{u}} c_{\mathrm{p}} D_{\mathrm{m}}=D_{\mathrm{T}} / D_{\mathrm{m}} c_{p}=\sum_{i=1}^{n} y_{i} c_{\mathrm{p}, \mathrm{i}}
$$

where $\lambda$ is the thermal conductivity of the mixture, $c_{\mathrm{p}}$ is the specific heat at constant pressure of the mixture, $\rho_{\mathrm{u}}$ is the density of unburned gas, $D_{\mathrm{T}}$ is the thermal diffusion coefficient of the mixture, and $D_{\mathrm{m}}$ is the mass diffusion coefficient of the deficient reactant to the inert gas, which can be calculated through Equation (7). The Lewis numbers of most test conditions in this study were greater than one; thus, nonlinear model I was predominantly used.

$$
D_{\mathrm{m}}=\frac{435.7 T^{3 / 2}}{p\left(V_{\mathrm{A}}^{1 / 3}+V_{\mathrm{B}}^{1 / 3}\right)^{2}} \sqrt{\frac{1}{\mu_{\mathrm{A}}}+\frac{1}{\mu_{\mathrm{B}}}},
$$

where $T$ is the initial temperature, $p$ is the initial pressure, $\mu_{A}$ and $\mu_{B}$ are the molar masses of $A$ and $B$, and $V_{\mathrm{A}}$ and $V_{\mathrm{B}}$ are the liquid molar volumes at normal boiling point of $\mathrm{A}$ and $\mathrm{B}$. The calculation was conducted using the Binary Components Diffusion Coefficient software V1.3 (Xi'an Weiwei Computer Technology Co. LTD [22]).

For the mixtures, the heat capacity and the thermal conductivity could be calculated as shown in Equations (8) and (9) [23], respectively.

$$
\begin{gathered}
c_{p}=\sum_{i=1}^{n} y_{i} c_{\mathrm{p}, \mathrm{i}} \\
\lambda=0.5\left[\sum_{i=1}^{n} x_{i} \lambda_{i}+\left(\sum_{i=1}^{n} x_{i} / \lambda_{i}\right)^{-1}\right]
\end{gathered}
$$

In Equation (8), $y_{\mathrm{i}}$ is the $i$-th component's mass fraction, and $c_{\mathrm{p}, \mathrm{i}}$ is the $i$-th component's heat capacity. In Equation (9), $x_{\mathrm{i}}$ is the $i$-th component's volume (mole) fraction, and $\lambda_{\mathrm{i}}$ is the $i$-th component's thermal conductivity. 
In this paper, nonlinear model I was applied because $L e>1$ was satisfied for all the test conditions. The Lewis number is also an essential parameter to evaluate the preferential diffusion instability of the flame as it is essentially a ratio of heat diffusion to mass diffusion. The preferential diffusion instability is stronger when there is a decrease in Le. Generally, the flame tends to be stable from the view of diffusion when $L e>1$, but the opposite is true when $L e<1$.

The laminar burning velocity $u_{\mathrm{L}}$ could be calculated as follows:

$$
u_{L}=S_{1}\left(\rho_{\mathrm{b}} / \rho_{\mathrm{u}}\right)=S_{1} / \sigma,
$$

where $\rho_{\mathrm{b}}$ and $\rho_{\mathrm{u}}$ are the density of burned and unburned gas, respectively. Their ratio is the thermal expansion ratio $\sigma$, shown in Equation (11). A decrease in $\sigma$ can lead to a weaker hydrodynamic instability.

$$
\sigma=\rho_{\mathrm{u}} / \rho_{\mathrm{b}}
$$

where $\rho_{\mathrm{u}}$ can be calculated through initial parameters, while $\rho_{\mathrm{b}}$ can be computed through a thermal equilibrium model in Chemkin-Pro.

Another parameter related to the hydrodynamic instability is the flame thickness $l_{\mathrm{f}}$, shown in Equation (12). A smaller flame thickness results in weaker self-bending and stronger gas torque at the flame front (equivalent torque when gas pressure acting on the flame front), thus leading to a stronger hydrodynamic instability [24].

$$
l_{\mathrm{f}}=\lambda / \rho_{\mathrm{u}} u_{\mathrm{L}} c_{\mathrm{p}}
$$

\subsection{Uncertainty Propagation}

In this work, inaccuracy was mainly caused by the error in Schlieren image recognition, ignition energy, and flame radiation [25]. The maximum error in Schlieren image recognition was 1 pixel, causing a maximum error of $0.083 \mathrm{~mm}$ in the flame radius. In this work, the minimum time interval was $0.33 \mathrm{~ms}$; thus, the maximum error in $S_{\mathrm{n}}$ was $25 \mathrm{~cm} \cdot \mathrm{s}^{-1}$, causing a potential maximum error of $5.7 \mathrm{~cm} \cdot \mathrm{s}^{-1}$ in $u_{\mathrm{L}}$. The inaccuracy brought about by ignition energy could be eliminated by selecting images with suitable radii, as stated in Section 3.1.

The effect of flame radiation could be calculated using Equation (13) [26].

$$
u_{\mathrm{L}, \mathrm{RCFS}}-u_{\mathrm{L}, \mathrm{EXP}}=0.82 u_{\mathrm{L}, \mathrm{EXP}}\left(u_{\mathrm{L}, \mathrm{EXP}} / S_{0}\right)^{-1.14}\left(T_{\mathrm{u}} / T_{0}\right)\left(p_{\mathrm{u}} / p_{0}\right)^{-0.3},
$$

where $S_{0}=0.01 \mathrm{~m} \cdot \mathrm{s}^{-1}, T_{0}=298 \mathrm{~K}, p_{0}=0.1 \mathrm{MPa}$, and $u_{\mathrm{L}, \mathrm{RCFS}}$ and $u_{\mathrm{L}, \mathrm{EXP}}$ are laminar burning velocities obtained experimentally taking radiation into account and measured practically, respectively. In this work, the inaccuracy caused by radiation did not exceed $0.7 \mathrm{~cm} \cdot \mathrm{s}^{-1}$, which was considered acceptable. All error bars of the burning velocity are highlighted in the figures below, indicating the possible maximum uncertainty.

\section{Results and Discussions}

\subsection{Laminar Burning Velocity and Markstein Length}

Figure 3 plots the comparison between the present results of laminar burning velocity and the available data from the literature; the error bars of the present results are also illustrated. It is interesting to see that the present results (the red thicker dashed line with error bars) show a similar trend to the results obtained by Liang (San Diego mechanism) [10], Katoch et al. (mesoscale diverging channel method) [15], Vancoillie et al. (heat flux method) [13], and Beeckmann et al. (constant volume chamber Schilieren method) [27]. All of these studies showed peak values at the equivalence ratio of 1.1-1.2. However, results from Liao et al. (constant volume chamber Schilieren method) [28] showed peak values at an equivalence ratio of 1.0. Note that the San Diego mechanism may overpredict the burning velocity of methanol. Metghalchi and Kech [29] also predicted higher burning velocity. The results in 
this study (the red thicker dashed line with error bars) were deemed acceptable for the analysis as the differences were not too significant considering the uncertainty.

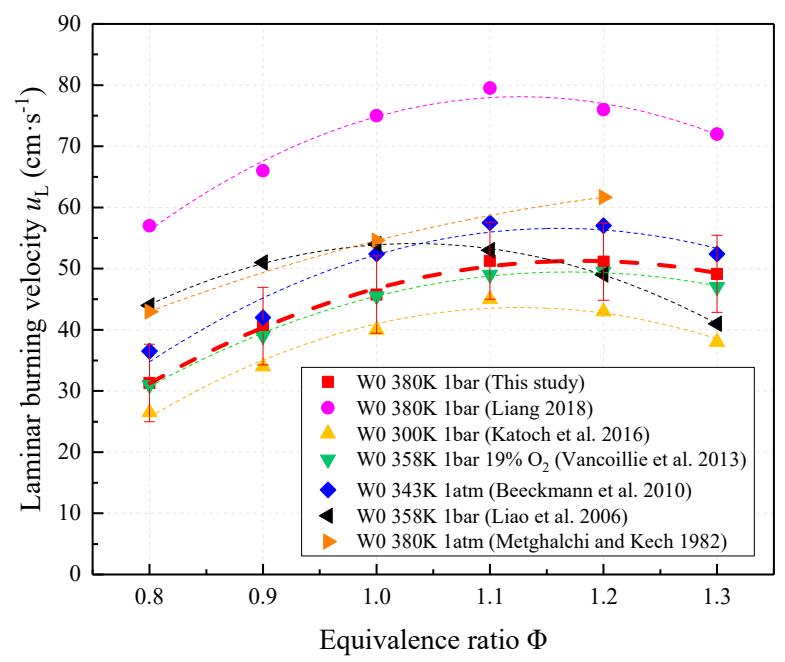

Figure 3. Comparison of the laminar burning velocity of methanol with available experimental data.

Figure 4 plots the laminar burning velocities at different pressures and temperatures, and curves of second-order polynomial fitting are also shown. It is clear to see that the laminar burning velocity increased with temperature but decreased with pressure. At the equivalence ratio of 1.0, when the pressure increased from 1 to 2 bar and then 2 to 4 bar, the burning velocity decreased by $15.8 \%$ and $15.4 \%$ at a stoichiometric ratio, respectively. When the temperature increased from $380 \mathrm{~K}$ to $450 \mathrm{~K}$, the burning velocity increased by $51.5 \%$ at a stoichiometric ratio. It is also interesting to see that, for the curves at the pressure of 1 bar and 2 bar, the peak burning velocity appeared at the equivalence ratio of 1.1-1.2, while the peak burning velocity appeared at the equivalence ratio of 1.2-1.3 for the curve of 4 bar. It is suspected that increasing the initial pressure may switch the peak burning velocity to the rich side, whereas the initial temperature has no effect.

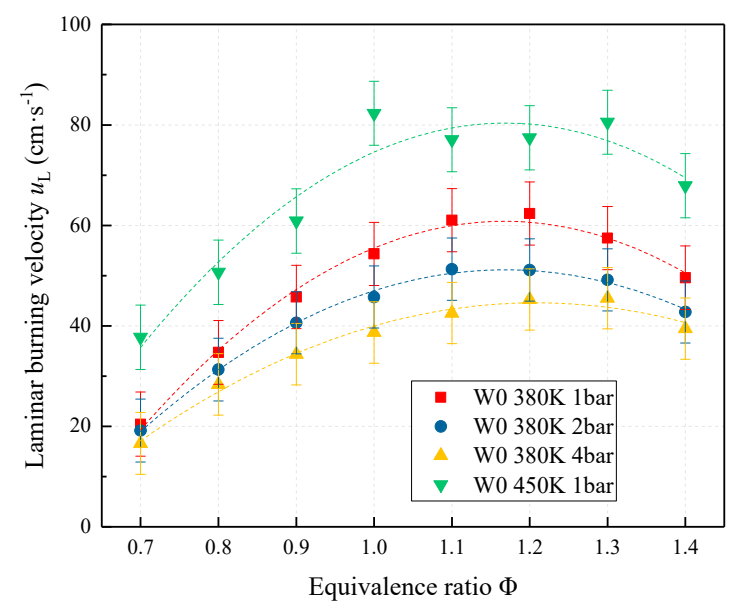

Figure 4. Laminar burning velocities at different pressures and temperatures.

Figure 5 shows the laminar burning velocities at different water fractions at a stoichiometric ratio. The laminar burning velocity decreased dramatically when the water fraction increased from $0 \%$ to $40 \%$, and it showed an approximately linear decrease as the water fraction increased linearly with an average $R^{2}$ value of 0.93601 . Among the results, the curve of $450 \mathrm{~K}, 1$ bar showed the highest degree of linearity with an $R^{2}$ value of 0.99939 . This agrees well with [13]. At initial conditions of $450 \mathrm{~K}, 1 \mathrm{bar}$, 
the laminar burning velocity decreased by $31.1 \%$ and $47.9 \%$ when the water fraction increased from $0 \%$ to $20 \%$ and then $40 \%$.

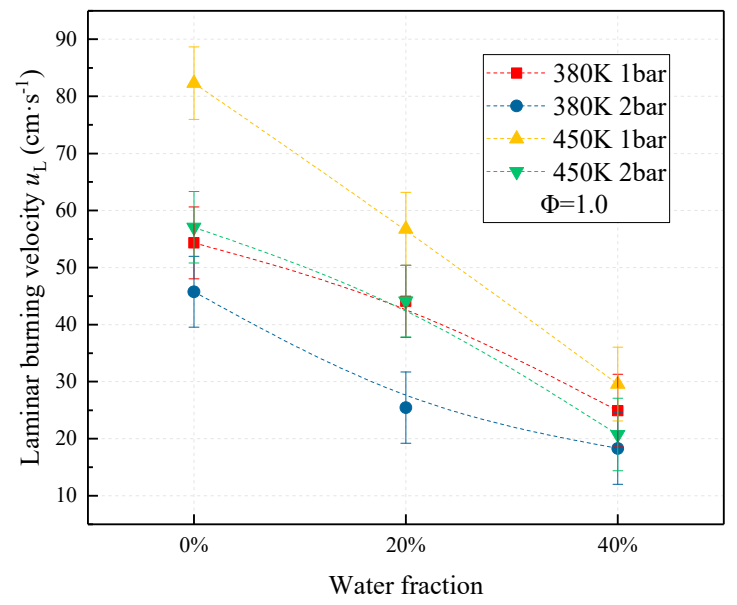

Figure 5. Laminar burning velocities at different water fractions at a stoichiometric ratio.

Figure 6 plots the Markstein lengths at different pressures, and linear fitting was applied to show the trend. It can be seen that Markstein length decreased with the equivalence ratio. According to $[30,31]$, Markstein length is mainly affected by the reactant which has a stronger diffusion capacity in the mixture. When the stronger diffusive component decreases, the flame becomes more sensitive to the stretching, thus decreasing the Markstein length and enhancing the tendency to be unstable. In this work, the diffusivity of oxygen into nitrogen was stronger than that of methanol into nitrogen. Therefore, with the equivalence ratio increasing, oxygen became relatively less while methanol became relatively more, leading to a declined Markstein length. It can also be seen that Markstein length decreased with pressure. Note that the flame tended to be unstable when $L_{\mathrm{b}}<0$ (and tended to be stable when $\left.L_{\mathrm{b}}>0\right)$, while the flame instability at the rich side $(\Phi>1.2)$ at a pressure of 4 bar was relatively strong.

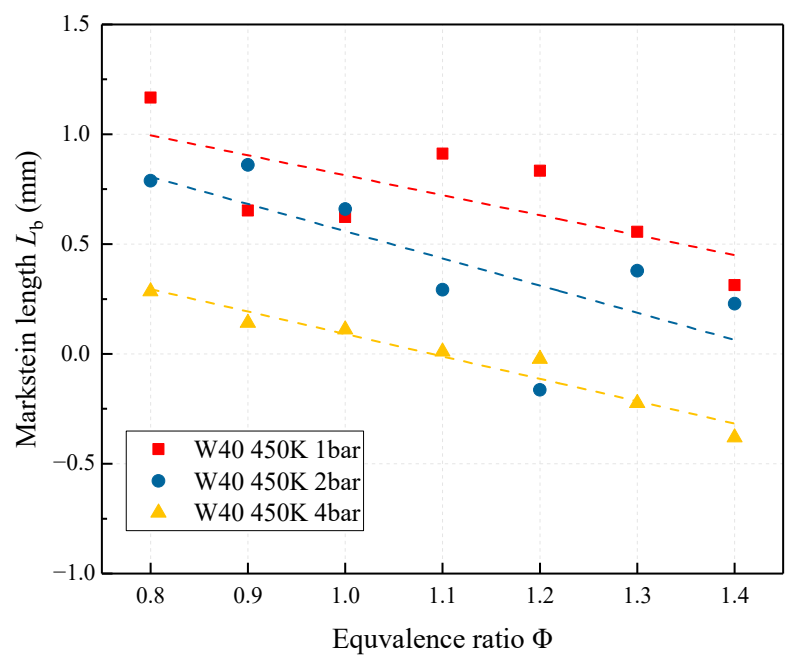

Figure 6. Markstein lengths at different pressures.

Figure 7 plots the Markstein lengths at different temperatures and water fractions at a stoichiometric ratio. Compared to the initial pressure, the initial temperature had a much weaker influence on Markstein length. Generally, with an increase in water fraction, the Markstein length increased slightly, thus giving the flame a trend of being stable. 


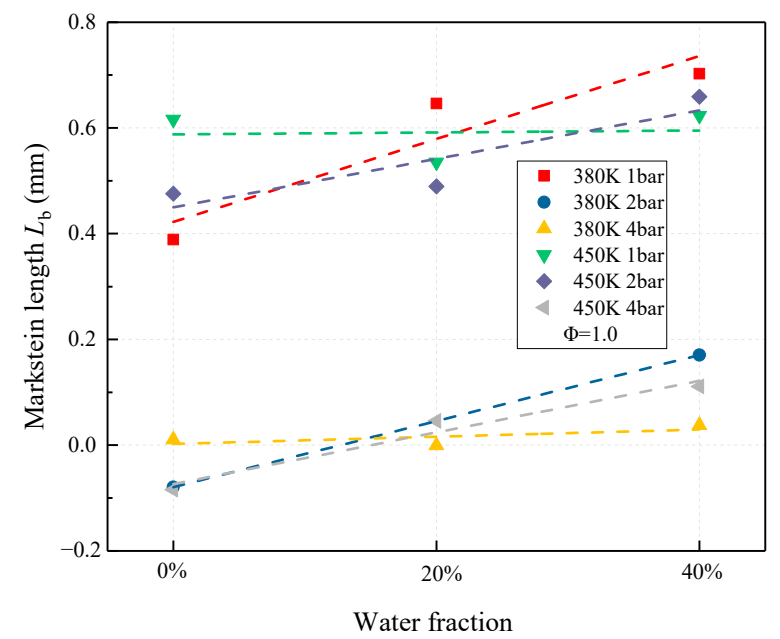

Figure 7. Markstein lengths at different temperatures and water fractions at a stoichiometric ratio.

\subsection{Flame Instability and Cellularity}

The flame instability can be classified as preferential diffusion instability, hydrodynamic instability, and buoyancy instability. Buoyancy instability happens at very low burning velocity, showing a floating spherical flame. Buoyancy instability was not considered in the present study as most test conditions for combustion analysis did not experience such a phenomenon. The preferential diffusion instability can be evaluated through the Lewis number. A decrease in Lewis number can enhance the preferential diffusion instability. The hydrodynamic instability can be evaluated through thermal expansion ratio and flame thickness. A smaller thermal expansion ratio and a larger flame thickness denote weaker hydrodynamic instability.

Figure 8 shows the Lewis numbers at different pressures and temperatures. It is clear that the Lewis number decreased with the equivalence ratio as the methanol increased while oxygen decreased (the same reason as for Markstein length according to [30,31]), resulting in an enhancement in preferential diffusion instability. It can also be seen that pressure had no influence on the Lewis number because diffusion was only affected by temperature. With temperature increasing, the Lewis number increased, as the enhancement in thermal diffusion was stronger than that in mass diffusion, leading to a suppression of preferential diffusion instability. At a stoichiometric ratio, the Lewis number increased by $4.6 \%$ when the temperature increased from $380 \mathrm{~K}$ to $450 \mathrm{~K}$.

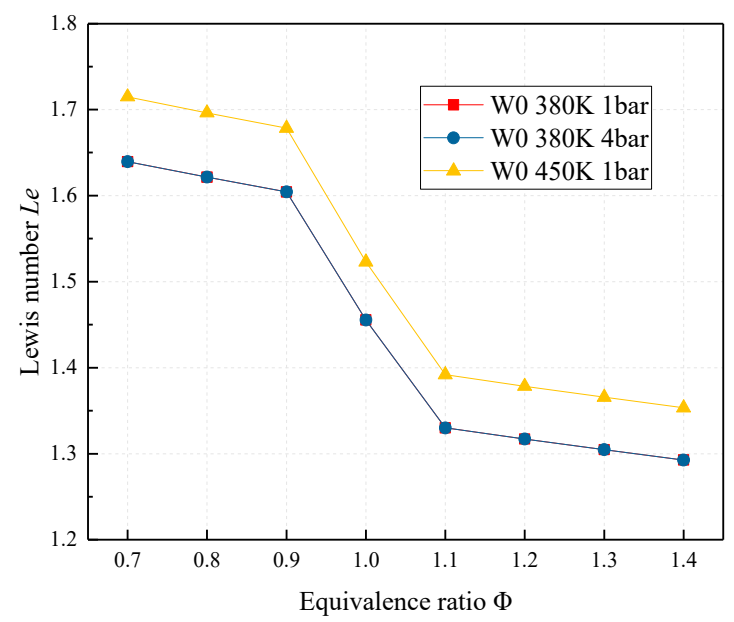

Figure 8. Lewis numbers at different pressures and temperatures.

Figure 9 plots Lewis numbers at different water fractions. It is clear that an increase in water fraction decreased the Lewis number, enhancing the trend of preferential diffusion instability. At a 
stoichiometric ratio, the Lewis number decreased by $10 \%$ and then a further $10 \%$ when the water fraction was increased from $0 \%$ to $20 \%$ and $40 \%$. It is also interesting to note that, with water fraction increasing, the trend of Lewis number decreasing with equivalence ratio became flatter. The Lewis number decreased by $0.36,0.3$, and 0.24 from $\Phi=0.7-1.4$ at water fractions of $0 \%, 20 \%$, and $40 \%$, respectively. Generally, as the Lewis numbers of all test conditions were greater than 1 , the preferential diffusion instability was weak.

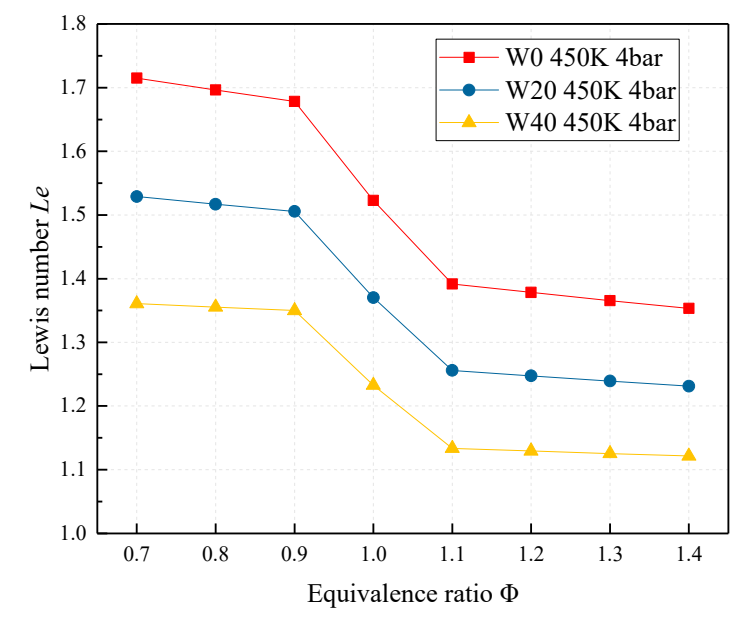

Figure 9. Lewis numbers at different water fractions.

Figure 10 shows the thermal expansion ratios and flame thicknesses at different pressures. It can be seen that, with pressure increasing, the thermal expansion ratio slightly increased and the flame thickness decreased significantly, both of which led to a stronger hydrodynamic instability. Therefore, increasing pressure can enhance the hydrodynamic instability. Furthermore, considering the more significant changes in flame thickness, it is clear that the flame thickness mainly affected the hydrodynamic instability when changing initial pressure.

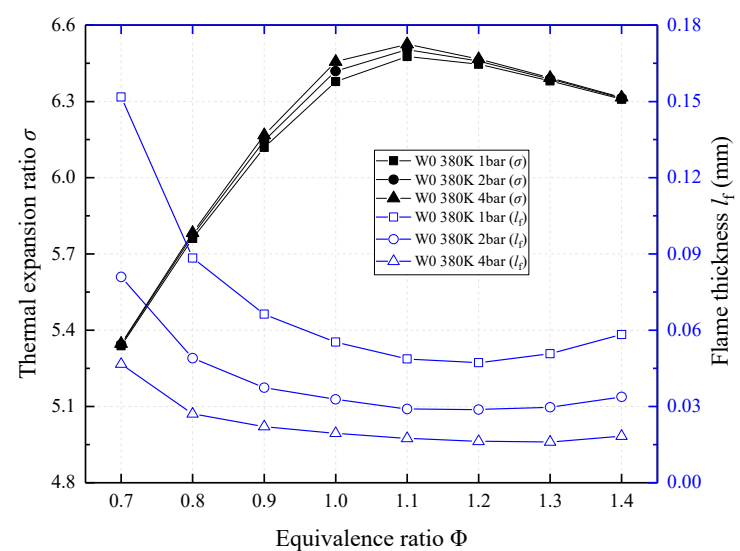

Figure 10. Thermal expansion ratios and flame thicknesses at different pressures.

Figure 11 shows the thermal expansion ratios and flame thicknesses at different temperatures. With the increase in temperature, the thermal expansion ratio decreased, indicating a suppression of hydrodynamic instability; however, the flame thickness also decreased, indicating an enhancement in hydrodynamic instability. It can be seen that the change in initial temperature caused a more significant change in thermal expansion ratio than flame thickness (apart from the very lean mixtures of $\Phi=0.7$ ). It can be inferred that the hydrodynamic instability is suppressed when elevating initial temperature, and the thermal expansion ratio mainly affects the hydrodynamic instability when changing initial temperature. 


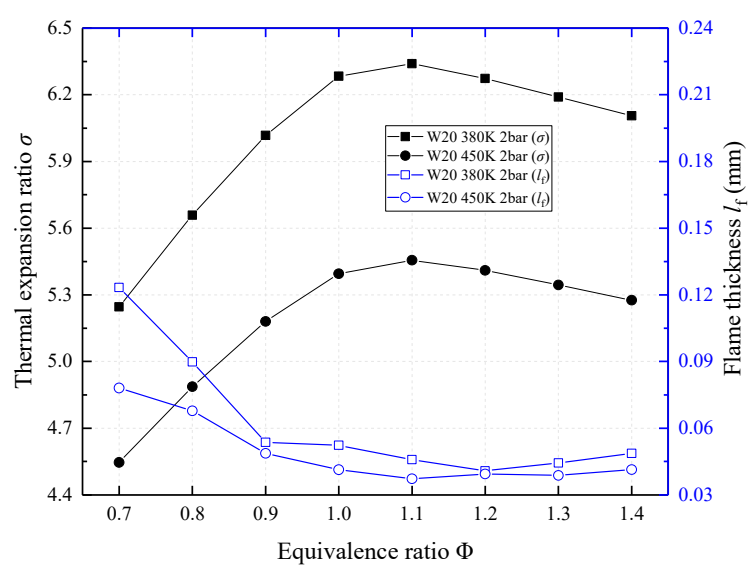

Figure 11. Thermal expansion ratios and flame thicknesses at different temperatures.

Figure 12 shows the thermal expansion ratios and flame thicknesses at different water fractions. It is clear that an increased water fraction led to a reduced thermal expansion ratio and an increased flame thickness, both of which led to a suppression of hydrodynamic instability. Therefore, the diluent effect of water can suppress the hydrodynamic instability of the methanol flame. It can also be seen that, with the equivalence ratio increasing from 0.7 to 1.4 , the expansion ratio increased first and then decreased, while the flame thickness decreased first and then increased, which indicates that the hydrodynamic instability was enhanced first and then suppressed. It is interesting to note that both the peak value of the expansion ratio and the trough value of the flame thickness appeared at $\Phi=1.0-1.2$, where the peak burning velocity happened. However, as increasing pressure and decreasing temperature (suppressing the burning velocity) enhance the hydrodynamic instability, a direct connection between the hydrodynamic instability and laminar burning velocity cannot be speculated.

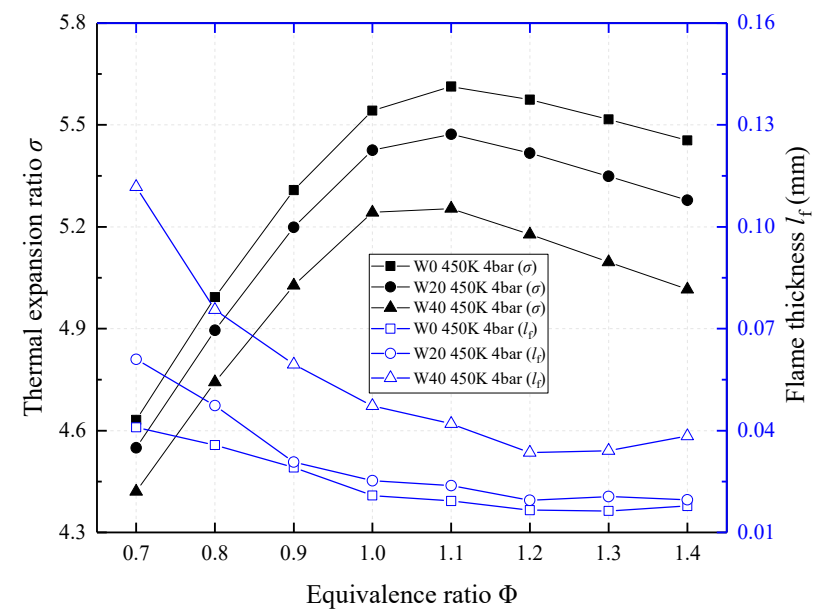

Figure 12. Thermal expansion ratios and flame thicknesses at different water fractions.

Figure 13 plots the onset time (after ignition) of cellularity at different pressures and temperatures. It is clear to see that, for most test conditions, an elevated pressure resulted in an earlier onset of cellularity. However, for the very lean mixture $(\Phi=0.7)$, a higher initial temperature led to an earlier onset of cellularity. Moreover, elevating the initial temperature could cause an earlier onset of cellularity in the whole equivalence ratio range. 


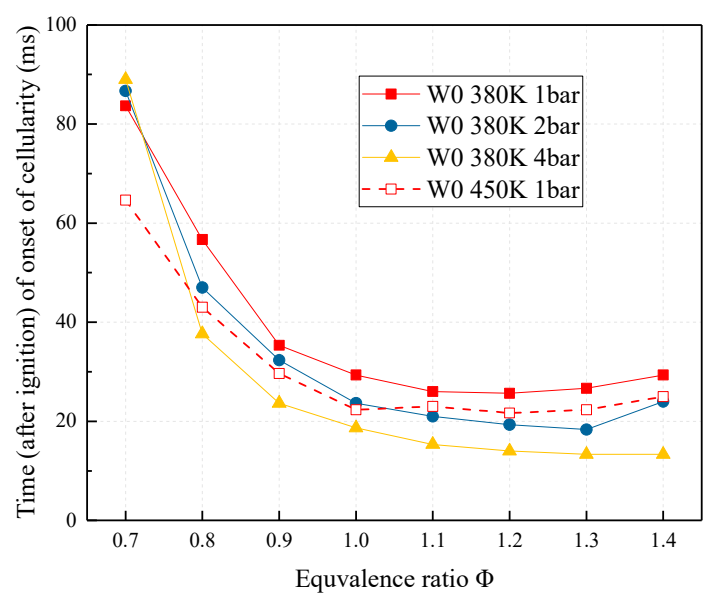

Figure 13. Onset of cellularity at different pressures and temperatures.

Figure 14 plots the onset time of cellularity at different water fractions. It is clear to see that a higher water fraction led to a later onset of cellularity. Unlike laminar burning velocity, the relationship between the onset time of cellularity and water fraction was not close to linear.

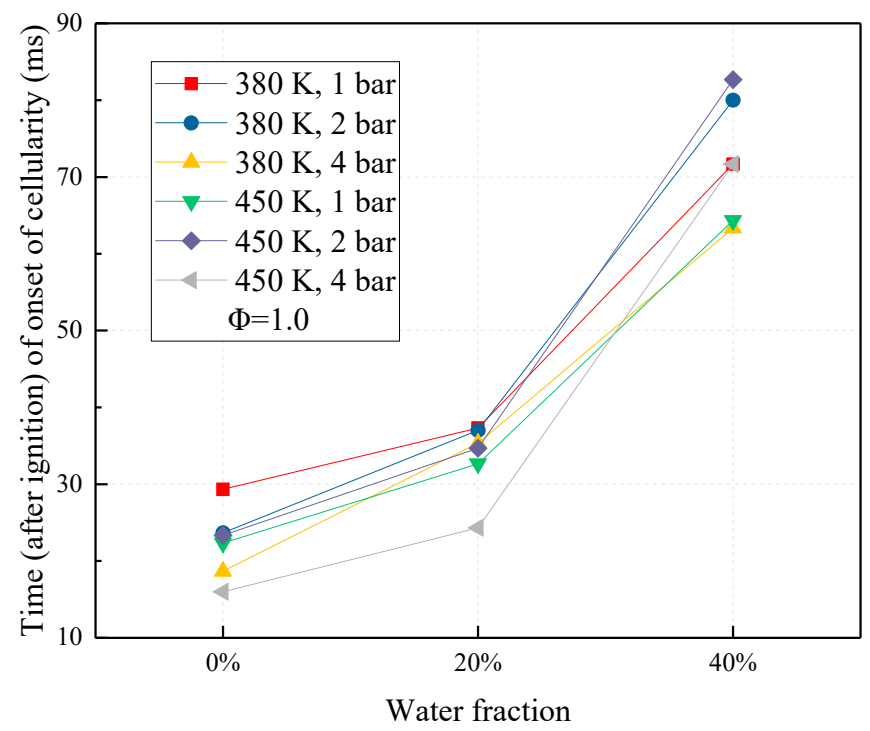

Figure 14. Onset of cellularity at different water fractions.

Comprehensively, increasing initial pressure had no effect on the preferential diffusion instability but enhanced the hydrodynamic instability, thus enhancing the general instability. Increasing initial temperature suppressed both preferential diffusion and hydrodynamic instability, thus suppressing the general instability. Increasing the water fraction enhanced the preferential diffusion instability but suppressed the hydrodynamic instability; thus, it is not clear how it affects the general instability. Note that increasing pressure or temperature could lead to an earlier onset of cellularity, while increasing water fraction could lead to a later onset, but there was no direct relationship between the onset of cellularity and general flame instability.

\section{Conclusions}

The laminar flame characteristics of hydrous methanol were experimentally studied using a constant volume chamber with a Schlieren system over a wide range of equivalence ratios, initial temperatures, and pressures at water fractions of $0-40 \%$. The laminar burning velocity, flame instability, and regularity of onset of cellularity were comprehensively investigated. Key conclusions are described below. 
(1) The laminar burning velocity of methanol increased with temperature and decreased with pressure. Increasing the initial pressure could switch the peak burning velocity to the rich side, while initial temperature had no effect. Burning velocity linearly decreased with water fraction at a stoichiometric ratio.

(2) Markstein length decreased with equivalence ratio and pressure. At rich mixtures under high pressures, the methanol flame tended to be more sensitive to stretch and, thus, unstable. An increase in water fraction could slightly increase the Markstein length.

(3) The Lewis number decreased with equivalence ratio, resulting in an enhancement in preferential diffusion instability. Pressure had no influence on Lewis number because diffusion was only affected by temperature. With the temperature increasing, Lewis number increased as the enhancement in thermal diffusion was stronger than that in mass diffusion. Increasing water fraction enhanced the preferential diffusion instability.

(4) Increasing the water fraction could lead to a decreasing thermal expansion ratio and an elevated flame thickness, both of which could lead to a suppression of hydrodynamic instability.

(5) A higher initial pressure led to an earlier onset of cellularity except in very lean mixtures, and a higher initial temperature could cause an earlier onset of cellularity over the whole equivalence ratio range. A higher water fraction led to a later onset of cellularity. There was no direct relationship between the onset of cellularity and general flame instability.

Author Contributions: Data curation, Z.Z.; Writing-Original draft preparation, Z.Z.; Visualization, Investigation, Z.M.; Methodology and Supervision, K.L. and X.C.; Software and Validation, H.S.; Writing-Reviewing and Editing, W.H. All authors have read and agreed to the published version of the manuscript.

Funding: This research received no external funding.

Conflicts of Interest: The authors declare no conflict of interest.

\section{References}

1. Xiao, P.; Lee, C.-F.; Wu, H.; Akram, M.Z.; Liu, F.; Akram, Z. Impacts of hydrogen-addition on methanol-air laminar burning coupled with pressures variation effects. Energy 2019, 187, 115997. [CrossRef]

2. Han, Z.; Zhu, Z.; Wang, P.; Liang, K.; Zuo, Z.; Zeng, D. The effect of initial conditions on the laminar burning characteristics of natural gas diluted by $\mathrm{CO}_{2}$. Energies 2019, 12, 2892. [CrossRef]

3. Chao, C.-Y.; Tsai, H.-W.; Pan, K.-L.; Hsieh, C.-W. On the microexplosion mechanisms of burning droplets blended with biodiesel and alcohol. Combust. Flame 2019, 205, 397-406. [CrossRef]

4. Liu, F.; Liu, Z.; Sang, Z.; He, X.; Liu, F.; Liu, C.; Xu, Y. Kinetic study of the effects of hydrogen blending to toluene reference fuel (TRF)/air mixtures on laminar burning velocity and flame structure. Fuel 2020, 274, 117850. [CrossRef]

5. Zervas, E.; Montagne, X.; Lahaye, J. Emissions of regulated pollutants from a spark ignition engine influence of fuel and air/fuel equivalence ratio. Environ. Sci. Technol. 2003, 37, 3232-3238. [CrossRef]

6. Zervas, E.; Montagne, X.; Lahaye, J. Influence of fuel and air/fuel equivalence ratio on the emission of hydrocarbons from a SI engine. 2. Formation pathways and modelling of combustion processes. Fuel 2004, 83, 2313-2321. [CrossRef]

7. Liang, K.; Stone, R. Laminar burning velocity measurement of hydrous methanol at elevated temperatures and pressures. Fuel 2017, 204, 206-213. [CrossRef]

8. Balki, M.K.; Sayin, C. The effect of compression ratio on the performance, emissions and combustion of an SI (spark ignition) engine fueled with pure ethanol, methanol and unleaded gasoline. Energy 2014, 71, 194-201. [CrossRef]

9. Chen, H.; Su, X.; He, J.; Xie, B. Investigation on combustion and emission characteristics of a common rail diesel engine fueled with diesel/n-pentanol/ methanol blends. Energy 2019, 167, 297-311. [CrossRef]

10. Liang, K. Numerical study of water effects on the laminar burning velocity of methanol. Biomass Bioenergy 2018, 108, 307-311. [CrossRef]

11. Lindstrom, F.; Angstrom, H.; Kalghatgi, G.; Moller, C.E. An empirical SI combustion model using laminar burning velocity correlations. SAE Tech. Pap. 2005, 144, 833-846. 
12. Farrell, J.T.; Weissman, W.; Johnston, R.J.; Nishimura, J.; Ueda, T.; Iwashita, Y. Fuel effects on SIDI efficiency and emissions. SAE Tech. Pap. 2003, 112, 2394-2412.

13. Vancoillie, J.; Christensen, M.; Nilsson, E.J.K.; Verhelst, S.; Konnov, A.A. The effects of dilution with nitrogen and steam on the laminar burning velocityof methanol at room and elevated temperatures. Fuel 2013, 105, 732-738. [CrossRef]

14. Li, J.; Zhao, Z.; Kazakov, A.; Chaos, M.; Dryer, F.L.; Scire, J.J., Jr. A comprehensive kinetic mechanism for CO, $\mathrm{CH} 2 \mathrm{O}$ and $\mathrm{CH} 3 \mathrm{OH}$ combustion. Int. J. Chem. Kinet. 2007, 39, 109-136. [CrossRef]

15. Katoch, A.; Asad, M.; Minaev, S.; Kumar, S. Measurement of laminar burning velocities of methanol-air mixtures at elevated temperatures. Fuel 2016, 182, 57-63. [CrossRef]

16. Chemical-Kinetic Mechanisms for Combustion Applications, Mechanical and Aerospace Engineering (Combustion Research), University of California at San Diego. Available online: http://combustion.ucsd.edu (accessed on 1 November 2020).

17. Han, Z.; Zhu, Z.; Yu, W.; Liang, K.; Zuo, Z.; Xia, Q.; Zeng, D. On the equivalent effect of initial temperature and pressure coupling on the flame speed of methane premixed combustion under dilution. Energy 2020, 207, 118269. [CrossRef]

18. Huang, Z.; Zhang, Y.; Zeng, K.; Liu, B.; Wang, Q.; Jiang, D. Measurements of laminar burning velocities for natural gas-hydrogen-air mixtures. Combust. Flame 2006, 146, 302-311. [CrossRef]

19. Chen, Z. On the extraction of laminar flame speed and Markstein length from outwardly propagating spherical flames. Combust. Flame 2011, 158, 291-300. [CrossRef]

20. Markstein, G.H. Experimental and theoretical studies of flame-front stability. Dyn. Curved Front. 1988, 18, 413-423. [CrossRef]

21. Kelley, A.P.; Law, C.K. Nonlinear effects in the extraction of laminar flame speeds from expanding spherical flames. Combust. Flame 2009, 156, 1844-1851. [CrossRef]

22. Binary Components Diffusion Coefficient V1.3, Xi'an Weiwei Computer Technology Co. LTD. Available online: http://www.htcsoft.com/ (accessed on 1 November 2020).

23. Mathur, S.; Tondon, P.K.; Saxena, S.C. Thermal conductivity of binary, ternary and quaternary mixtures of rare gases. Mol. Phys. 1967, 6, 569-579. [CrossRef]

24. Kwon, O.; Rozenchan, G.; Law, C. Cellular instabilities and self-acceleration of outwardly propagating spherical flames. Proc. Combust. Inst. 2002, 29, 1775-1783. [CrossRef]

25. Zuo, Z.; Pei, Y.; Qin, J.; Xu, H.; Lu, L. Laminar burning characteristics of premixed methane-dissociated methanol-air mixtures under lean burn conditions. Appl. Therm. Eng. 2018, 140, 304-312. [CrossRef]

26. Cai, X.; Wang, J.; Zhang, W.; Xie, Y.; Zhang, M.; Huang, Z. Effects of oxygen enrichment on laminar burning velocities and Markstein lengths of $\mathrm{CH} 4 / \mathrm{O} 2 / \mathrm{N} 2$ flames at elevated pressures. Fuel 2016, 184, 466-473. [CrossRef]

27. Beeckmann, J.; Cai, L.; Pitsch, H. Experimental investigation of the laminar burning velocities of methanol, ethanol.; n-propanol, and n-butanol at high pressure. Fuel 2014, 117, 340-550. [CrossRef]

28. Liao, S.Y.; Jiang, D.M.; Huang, Z.H.; Zeng, K. Characterization of laminar premixed methanol-air flames. Fuel 2006, 85, 1346-1353. [CrossRef]

29. Metghalchi, M.; Keck, J.C. Burning velocities of mixtures of air with methanol, isooctane, and indolene at high pressure and temperature. Combust. Flame 1982, 48, 191-210. [CrossRef]

30. Manton, J.; Elbe, G.V.; Lewis, B. Burning-velocity measurements in a spherical vessel with central ignition. Symp. Combust. 1953, 4, 358-363. [CrossRef]

31. Prathap, C.; Ray, A.; Ravi, M.R. Investigation of nitrogen dilution effects on the laminar burning velocity and flame stability of syngas fuel at atmospheric condition. Combust. Flame 2008, 155, 145-160. [CrossRef]

Publisher's Note: MDPI stays neutral with regard to jurisdictional claims in published maps and institutional affiliations. 